\title{
Uterine Metabolism of the Conscious Gilt during Late Pregnancy
}

\author{
PIERRE HENRI DUÉE, CARLOS SIMOES NUNES, JEAN-PAUl PÉGORIER, MARC GILBERT, \\ AND JEAN GIRARD \\ Centre de Recherches sur la Nutrition, C.N.R.S., Meudon-Bellevue [P-H.D., J-P.P., J.G.], Laboratoire de \\ Physiologie de la Nutrition, INRA, Jouy-en-Josas [C.S.N.] and College de France, Paris, France [M.G.]
}

\begin{abstract}
The present study provides some metabolic features of the gravid uterus in the nonanesthetized gilt during the last fourth portion of pregnancy. Substrate and oxygen arteriovenous differences across the uterus were determined in eight gilts with chronically implanted arterial and uterine venous catheters. Glucose represents the main substrate taken up by the conceptus and glucose extraction amounts to $8.3 \pm 0.5 \%$. By contrast, there is a constant release of lactate from the pregnant uterus. The coefficient of extraction of oxygen is $20.2 \pm 1.9 \%$. Glucose plus lactate/oxygen quotient is high $(1.3 \pm 0.2)$, suggesting that glucose alone is sufficient to account for the oxidative metabolism of the pig uterus. Nonesterified fatty acid and ketone body are not significantly extracted by the pig uterus whereas a significant amino acid extraction occurs in late pregnancy. Uterine uptake of amino acids depends on maternal arterial concentrations and a great part (78\%) of this uterine uptake is represented by neutral amino acids and especially glutamine. (Pediatr Res 22: 587-590, 1987)
\end{abstract}

Comparative study of the uterine metabolism in pregnant mammals results in a better knowledge of the nutritional demand imposed by the growing conceptus, according to the type of placentation, the rate of fetal growth, and the nature of fetal body composition. In this field, most of the data have been performed on sheep (1) and to a much lower extent in small nonruminant mammals, the guinea pig $(2)$ and the rabbit $(3,4)$. The present study provides data on substrate and oxygen uptake by the gravid uterus of the pregnant pig which could represent an interesting large nonruminant mammal to compare with the other species previously studied. Gestation in the pig is characterized by the production of a large litter during 114 days corresponding, at term, to a small fetomaternal weight ratio ( 10 to $15 \%$ ). The body composition of the pig fetus at term presents a low fat content as in the sheep, whereas rabbit or guinea pig fetuses are well endowed with fat stores. Although the type of placentation is considered as analogous in pig and ruminants, i.e. epitheliochorial, a more accurate study based on the morphometry of the placenta has underlined striking differences between species (5), strengthening the rationale for developing a chronically catheterized model in the pig.

\section{MATERIALS AND METHODS}

The experiments were performed on eight Large White pregnant gilts (premating weight $115 \pm 2 \mathrm{~kg}$ ) fed on a diet based on

Received April 24, 1987; accepted July 2, 1987.

Correspondence and reprint requests Pierre-Henri Duée, Centre de Recherches sur la Nutrition, CNRS, 9 ruc Jules Hetzel, 92190 Meudon-Bellevue, France.

Supported in part by a Program Grant on Perinatality from the Institut National de la Recherche Agronomique. corn, soybean meal, and alfalfa meal (crude protein $130 \mathrm{~g} / \mathrm{kg}$; digestible energy $12.8 \mathrm{MJ} \mathrm{de} / \mathrm{kg}$ ) at a level of $2 \mathrm{~kg} /$ day. On day 85 of pregnancy, the gilts were submitted to general anaesthesia by inhalation of halothane (3\%; I.C.I. Pharma, Enghier, France) and a mixture of oxygen and nitrogen protoxide $(2: 3)$ by means of a semiclosed circuit apparatus. After lateral laparotomy, a fetoplacental unit located in second or third position from the cervical end of the right uterine horn was exteriorized under sterile conditions and a polyvinyl catheter $(1.27-\mathrm{mm}$ internal diameter and 2.29-mm external diameter) was introduced into a branch of the uterine vein in the direction of the blood flow. Three to five $\mathrm{cm}$ of catheter were inserted in the uterine vein, so that the tip was beyond the meeting points with other collateral vessels. Anatomically, this catheter position, located far from the main uterine vein junction, avoids an eventual mixing with nonplacental blood and does permit to sample only the blood from one fetoplacental unit. This assessment is supported when concentrations of glucose, lactate, alanine, or glycerol were measured in blood sampled from two catheterized uterine vessels from two adjacent fetoplacental units. When venous blood was collected simultaneously, differences in the substrate concentrations do not exceed $1 \%$ (data not shown). Another polyethylene catheter $(1.77 \mathrm{~mm}$ inner diameter and $2.80 \mathrm{~mm}$ external diameter) was inserted into the right carotid artery. Both catheters were fixed by two internal ligatures, exteriorized, and maintained in separate fixed plastic bags. Daily flushing with a heparin-saline solution $(100 \mathrm{U} / \mathrm{ml})$ allowed to keep both catheters patent until the end of pregnancy (i.e. 114 days). After surgery, animals were kept in individual cages and recovered their preoperative level of food intake $(2 \mathrm{~kg} /$ day in two meals at $0900 \mathrm{~h}$ and $1600 \mathrm{~h})$ within 2 days after surgery. Water was given ad libitum. Pregnant gilts gained $11.0 \pm 1.8 \mathrm{~kg}$ from surgery until parturition and delivered an average litter of $7.9 \pm 0.5$ piglets with a mean body weight of $1.1 \pm 0.1 \mathrm{~kg}$. Taking into account previous data on fetal pig development (6), the growth of the conceptus in the pig corresponded to $45 \%$ of the maternal weight gain during this period. Every 3 days, after an overnight fast, arterial and venous blood samples were drawn simultaneously from day 90 of pregnancy until parturition for determination of blood glucose, lactate, glycerol, acetoacetate, B-hydroxybutyrate, alanine, and plasma nonesterified fatty acid and urea. Around day 100 of pregnancy, two additional arterial and venous blood samples were withdrawn for determination of blood oxygen, glucose, lactate, and amino acids.

Chemical methods. Blood substrate determinations were performed by standard enzymatic methods previously described (7). Blood oxygen content was measured with a Lex- $\mathrm{O}_{2}-\mathrm{CON}$ (Lexington Instruments, Waltham, MA). Plasma nonesterified fatty acids were determined by a radiochemical microtechnique (8) and the analysis of amino acids in the whole blood was performed on ethanol filtrates using an automated ion-exchange-chromatographic technique (Liquimat 3, Kontron AG, Zürich, Switzerland). To prevent glutamine degradation before and during 
analysis, samples were stored at $-80^{\circ} \mathrm{C}$ and the column temperature maintained at $31^{\circ} \mathrm{C}$ for glutamine analysis. Moreover, an accurate separation of glutamine and glutamic acid was obtained by using lithium buffers. In these conditions, reproductibility of amino acid analysis was estimated by the average coefficient of variation for all the amino acids including glutamine (3.9 \pm $0.3 \%$ ) from repeated five blood sample analyses. Substrate arterial concentrations and arteriovenous differences were listed in five classes depending on the gestational age and corresponding to one or two blood samples per animal. The coefficient of extraction has been calculated as the substrate arteriovenous difference in percentage of the related arterial concentration.

To estimate the maximum contribution of glucose and lactate to oxygen consumption by the gravid uterus, metabolic quotients have been calculated by the ratio substrate/oxygen arteriovenous differences, multiplied by a constant, indicating the number of moles of oxygen which are required for complete oxidation to $\mathrm{CO}_{2}$ and water of $1 \mathrm{~mol}$ of this substrate (1). Values of this constant are 3 for lactate and 6 for glucose.

Results are expressed as means with their SEs. Statistical analyses were performed by using an analysis of variance to establish the significance of changes in the substrate arterial concentrations in relation with the age of gestation. To check the significance of substrate arteriovenous differences, the Wilcoxon's test has been applied within each class of gestational age (9).

\section{RESULTS}

Table 1 shows arterial concentrations of blood glucose and lactate, and the respective uterine arteriovenous differences. After an overnight fast, arterial glucose concentration remained constant between 90 and 110 days of pregnancy. On the contrary, arterial lactate concentration increased steadily until parturition and at day 110 became significantly different from the day- 90 value. Lactate concentrations were higher in the uterine vein than in the artery, reflecting a small but constant release of lactate from the pregnant uterus. By contrast, the glucose uterine arteriovenous differences were always positive and remained relatively constant during the experimental period, reflecting an average coefficient of extraction of $8.3 \pm 0.5 \%$. The variation of this coefficient due to intraanimal variation (i.e. gestational age) amounted for only $20 \%$ of the total variance, while the variance due to the differences between animals represented $35 \%$ of the total variance.

Table 2 shows metabolic quotients determined around day 100 , which corresponds to $85-90 \%$ of gestation. The arterial oxygen concentration was significantly higher than the venous oxygen concentration $(p<0.01)$. The coefficient of extraction of oxygen was $20.2 \pm 1.9 \%$. The glucose/oxygen quotient was $1.7 \pm 0.2$ whereas the glucose + lactate/oxygen quotient was 1.3 \pm 0.2 . Table 3 shows the changes in fat-derived substrates. Blood ketone bodies correspond to the sum of acetoacetate and Bhydroxybutyrate. Arterial concentrations of plasma nonesterified fatty acids, blood ketone bodies, and glycerol were constant during the experimental period. No statistical arteriovenous difference for nonesterified fatty acids and ketone bodies was found. The coefficient of extraction for nonesterified fatty acids was less than $4 \%$. In contrast, a positive arteriovenous difference for glycerol was found during the experimental period and the corresponding coefficient of extraction was $12.6 \pm 1.3 \%$. Among free amino acids, a longitudinal study was made only for alanine (Table 4). Arterial alanine concentration, determined by an enzymatic method, strikingly increased in late pregnancy and the alanine arteriovenous difference displayed a constant positive value. The arterial plasma urea concentration was constant during the experimental period but a significant negative arteriovenous difference was observed only a few days before parturition (Table 4).

Data for blood amino acids around day 100 of pregnancy are shown in Table 5. Although the chromatographic method leads to an accurate determination of amino acid concentrations, the uterine arteriovenous difference for several amino acids was not significantly different from zero. This was probably due to the low number of observations $(n=16)$. Nevertheless the uterine arteriovenous difference of total amino acids amounted to 178 $\pm 30 \mu \mathrm{mol} /$ liter $(n=16)$, representing an extraction of $4.7 \pm$ $0.8 \%$ (range 0.5 to $10.1 \%$ ) across the uterine circulation. A majority $(78 \%)$ of this uterine uptake was represented by neutral amino acids and especially glutamine. In contrast, no significant uptake of acidic amino acids by the pregnant uterus was found. The uterine arteriovenous difference for each amino acid depended on the corresponding maternal arterial concentration. A linear relationship $(r=0.91)$ existed for each amino acid, except glutamine and glutamate, between uterine arteriovenous difference and arterial concentrations.

\section{DISCUSSION}

The present study provides information about the metabolic activity of the gravid uterus in the nonanesthetized gilt. Similar observations have been made in several mammalian species: ewe (10), cow $(11,12)$, mare $(13)$, rabbit, $(3,4,14)$, guinea pig $(2$, $15)$, differing in the rate of fetal growth, the fetal body composi-

Table 2. Arterial concentration, uterine arteriovenous difference of oxygen, glucose, and lactate and related metabolic quotients*

\begin{tabular}{cccr} 
Substrate & $\begin{array}{c}\text { Arterial concentration } \\
(\mathrm{mM})\end{array}$ & $\begin{array}{c}\text { Arteriovenous } \\
\text { difference } \\
(\mathrm{mM})\end{array}$ & \multicolumn{1}{c}{$\begin{array}{c}\text { Metabolic } \\
\text { quotient }\end{array}$} \\
\hline Oxygen & $4.93 \pm 0.12$ & $1.01 \pm 0.11$ & \\
Glucose & $4.17 \pm 0.09$ & $0.27 \pm 0.03$ & $1.7 \pm 0.2$ \\
Lactate & $0.93 \pm 0.04$ & $-0.12 \pm 0.02$ & $-0.4 \pm 0.1$ \\
\hline
\end{tabular}

$*$ Values are means \pm SEM of two determinations per animal $(n=8)$ around day 100 of pregnancy.

Table 1. Arterial concentration $(A)$ and uterine arteriovenous difference $(A-V)$ of glucose and lactate*

\begin{tabular}{lrrrrr}
\hline Gestational age (days) & 90 & 95 & \multicolumn{1}{c}{100} & \multicolumn{1}{c}{105} \\
\hline Substrate (mmol/liter) & & & & & \\
Glucose & & & & \\
A & $4.12 \pm 0.16$ & $4.15 \pm 0.10$ & $3.99 \pm 0.10$ & $4.13 \pm 0.09$ & $4.15 \pm 0.13$ \\
A-V & $0.30 \pm 0.09$ & $0.32 \pm 0.05$ & $0.35 \pm 0.04$ & $0.35 \pm 0.04$ & $0.41 \pm 0.07$ \\
Lactate & & & & & \\
A & $0.76 \pm 0.04$ & $0.89 \pm 0.03$ & $0.94 \pm 0.04$ & $0.92 \pm 0.03$ & $1.01 \pm 0.06 \dagger$ \\
A-V & $-0.08 \pm 0.02$ & $-0.13 \pm 0.02$ & $-0.15 \pm 0.02$ & $-0.10 \pm 0.02$ & $-0.13 \pm 0.02$ \\
\hline
\end{tabular}

*Values are mean \pm SEM of one or two determinations per animal $(n=8)$ for each gestational age. Day 90 represents the period between day 90 and 94.

$\dagger$ Day 110 significantly different from day 90 value $(p<0.05)$. Glucose and lactate arteriovenous differences are significantly different from zero $(p<0.01)$. 
Table 3. Arterial concentration (A) and uterine arteriovenous difference $(A-V)$ of nonesterified fatty acids, ketone bodies, and glycerol*

\begin{tabular}{|c|c|c|c|c|c|}
\hline Gestational age (days) & 90 & 95 & 100 & 105 & 110 \\
\hline \multicolumn{6}{|l|}{ Substrate ( $\mu \mathrm{mol} /$ liter $)$} \\
\hline \multicolumn{6}{|l|}{ Nonesterified fatty acids } \\
\hline A & $224 \pm 22$ & $221 \pm 11$ & $226 \pm 14$ & $\begin{array}{c}220 \pm 13 \\
10+5\end{array}$ & $\begin{array}{c}239 \pm 25 \\
7+5\end{array}$ \\
\hline 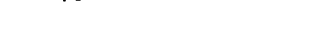 & $1+3$ & $9 \pm 0$ & $y \pm J$ & & $1-5$ \\
\hline \multicolumn{6}{|l|}{ Ketone bodies } \\
\hline A & $40 \pm 7$ & $43 \pm 4$ & $43 \pm 4$ & $54 \pm 4$ & $52 \pm 3$ \\
\hline$A-V$ & $1 \pm 3$ & $6 \pm 3$ & $-2 \pm 3$ & $13 \pm 3$ & $5 \pm 2$ \\
\hline \multicolumn{6}{|l|}{ Glycerol } \\
\hline A & $242 \pm 14$ & $232 \pm 8$ & $216 \pm 16$ & $216 \pm 7$ & $216 \pm 12$ \\
\hline$A-V$ & $40 \pm 12$ & $22 \pm 6$ & $30 \pm 7$ & $28 \pm 5$ & $22 \pm 6$ \\
\hline
\end{tabular}

* See Table 1 for explanations. Glycerol arteriovenous difference is significantly different from zero $(p<0.05)$.

Table 4. Arterial concentration $(A)$ and uterine arteriovenous difference $(A-V)$ of alanine and urea*

\begin{tabular}{cccccr}
\hline Gestational age (days) & 90 & 95 & 100 & 105 & \\
\hline Substrate (mmol/liter) & & & & & \\
Alanine & & & & & \\
A & $0.29 \pm 0.02$ & $0.34 \pm 0.01$ & $0.36 \pm 0.02$ & $0.38 \pm 0.02$ & $0.50 \pm 0.03 \dagger$ \\
A-V & $0.03 \pm 0.01$ & $0.02 \pm 0.01$ & $0.03 \pm 0.01$ & $0.04 \pm 0.01$ & $0.04 \pm 0.01$ \\
Urea & & & & \\
A & $2.34 \pm 0.20$ & $2.57 \pm 0.10$ & $2.51 \pm 0.13$ & $2.41 \pm 0.10$ & $2.38 \pm 0.09$ \\
A-V & $-0.02 \pm 0.02$ & $0.05 \pm 0.02$ & $0.00 \pm 0.01$ & $-0.01 \pm 0.01$ & $-0.14 \pm 0.07$ \\
\hline
\end{tabular}

* See Table 1 for explanations. rom zero $(p<0.05)$.

Table 5. Arterial concentration and uterine arteriovenous difference of blood amino acids ( $\mu$ mol/liter)*

\begin{tabular}{|c|c|c|c|}
\hline Amino acid & $\begin{array}{c}\text { Arterial } \\
\text { concentration }\end{array}$ & $\begin{array}{l}\text { Arteriovenous } \\
\text { difference }\end{array}$ & $\begin{array}{l}\text { Coefficient of } \\
\text { extraction } \\
(\%)\end{array}$ \\
\hline \multicolumn{4}{|l|}{ Acidic } \\
\hline Aspartic acid & $67 \pm 5$ & $2 \pm 2$ & 3.1 \\
\hline Glutamic acid & $229 \pm 11$ & $1 \pm 1$ & 0.4 \\
\hline Taurine & $345 \pm 20$ & $-1 \pm 2$ & -0.2 \\
\hline \multicolumn{4}{|l|}{ Neutral } \\
\hline Threonine & $137 \pm 12$ & $7 \pm 2 \dagger$ & 5.1 \\
\hline Serine & $112 \pm 6$ & $4 \pm 2$ & 3.6 \\
\hline Asparagine & $49 \pm 7$ & $3 \pm 2$ & 6.1 \\
\hline Glutamine & $257 \pm 13$ & $46 \pm 5 \ddagger$ & 17.9 \\
\hline Glycine & $680 \pm 14$ & $25 \pm 5 \dagger$ & 3.7 \\
\hline Alanine & $352 \pm 33$ & $11 \pm 3 \dagger$ & 3.1 \\
\hline Cystine & $47 \pm 4$ & $3 \pm 1$ & 6.4 \\
\hline Methionine & $27 \pm 3$ & $3 \pm 1$ & 11.1 \\
\hline$\alpha$-Aminobutyric acid & $19 \pm 2$ & $0 \pm 2$ & 0.0 \\
\hline Valine & $269 \pm 15$ & $18 \pm 3 \ddagger$ & 6.7 \\
\hline Isoleucine & $125 \pm 7$ & $5 \pm 2$ & 4.0 \\
\hline Leucine & $143 \pm 6$ & $4 \pm 2$ & 2.8 \\
\hline Tyrosine & $66 \pm 4$ & $3 \pm 1$ & 4.5 \\
\hline Phenylalanine & $66 \pm 5$ & $5 \pm 2$ & 7.6 \\
\hline \multicolumn{4}{|l|}{ Basic } \\
\hline Lysine & $201 \pm 9$ & $13 \pm 2 \ddagger$ & 6.5 \\
\hline Histidine & $82 \pm 3$ & $6 \pm 2 \dagger$ & 7.3 \\
\hline 3-Methyl histidine & $35 \pm 3$ & $-3 \pm 2$ & -8.6 \\
\hline Arginine & $100 \pm 8$ & $7 \pm 2 \uparrow$ & 7.0 \\
\hline Citrulline & $64 \pm 3$ & $3 \pm 1$ & 4.7 \\
\hline Ornithine & $133 \pm 13$ & $9 \pm 2+$ & 6.8 \\
\hline
\end{tabular}

* Values are means \pm SEM of two determinations per animal $(n=8)$ around day 100 of pregnancy.

$+p<0.05$ and $\ddagger p<0.01$ significantly different from zero tion, and the placental structure which, in turn, may alter the nutritional demand of the developing conceptus.

During the last fourth of pregnancy, glucose represents quantitatively the main substrate taken up by the conceptus as previously shown in other species. The glucose uterine arteriovenous difference remains constant during the last part of pregnancy in the pig as in the rabbit (14), whereas it slightly increases in the ewe (16). Nevertheless, it is interesting to notice that the coefficients of extraction of glucose $(8.3 \%)$ or oxygen $(20.2 \%)$ across the uterus are similar in the pig and sheep (10) in late pregnancy. Maternal arterial glucose concentration is lower in ruminants than in the pig but the extraction of glucose across the uterus of the pregnant ewe remains constant over a wide range of plasma glucose concentrations (17). However, the coefficients of extraction for glucose and oxygen in the pig and sheep are much lower than those measured in the rabbit (4) or guinea pig (2). Whether these differences between species are related to differences in placental structure needs further examination.

Another general feature of uterine metabolism found in pig, as in other species, is a continuous output of lactate in the uterine vein. In the pig this represents about $15-20 \%$ of the glucose arteriovenous difference, assuming no lactate production in uteroplacental tissues from other sources than maternal glucose. Similar data have been found in ruminants $(10,11)$. The placenta is a major site of uterine oxygen and glucose utilization, and is a net producer of lactate (10). The present data suggest a close agreement between pig and sheep concerning some parameters linked to the metabolic activity of the placenta. Another point of interest in this study is the observation of a high metabolic quotient for glucose, even after correction for the lactate released $(1.3 \pm 0.2)$. This suggests that the uterine glucose uptake is largely sufficient to account for the total oxidative metabolism of the uterus and its content. This result is not in agreement with previous data obtained in anesthetized pregnant pig (18) showing a low metabolic quotient for glucose. This also differs from data obtained in other species $(4,10,11)$ and underlines the role of glucose as the only oxidative substrate in the pregnant uterus of 
the pig since other substrates (nonesterified fatty acids, ketone bodies) are not taken up by the conceptus to a significant extent or are poorly oxidized (amino acids). This feature of the pig uterine metabolism could be altered a few days before parturition since the uterine urea release becomes significant at this time.

As mentioned above, nonesterified fatty acids do not represent a quantitatively important substrate for the pregnant uterus and this also agrees with a very low body fat content of fetal pigs. Such a relationship has been previously found in the sheep (19) but not in the rabbit (14) or in the guinea pig (2), which bear fetuses with a much higher body fat content. By contrast, a significant extraction of amino acids by the conceptus is present in late pregnancy and for each amino acid, the uterine uptake depends on its maternal arterial concentration as also demonstrated for the sheep (20). Nevertheless, the amino acid arteriovenous difference across the uterus is twice as high for the pig as for the sheep (20). The uterine blood flow relative to the fetal weight in late gestation is in the same range in pig and sheep: 0.3 to $0.4 \mathrm{liter} / \mathrm{min} / \mathrm{kg}$ in pig $(21,22), 0.35 \mathrm{liter} / \mathrm{min} / \mathrm{kg}$ in sheep (10), which is 2 - to 3 -fold higher than the corresponding value in the rabbit (4) or guinea-pig $(2,23)$. Thus, this different uterine amino acid extraction might be explained by the twice as high rate of protein accretion in fetal tissues in the pig (6) as in the lamb (24).

Finally, the impact of gestation; as described by the metabolic demand of the pregnant uterus, on maternal metabolism in the pig may be estimated by a longitudinal determination of arterial substrate concentrations. As previously found (25), pregnant gilts exhibit constant blood glucose, glycerol, and plasma nonesterified fatty acid concentrations, with a concomitant increase in blood alanine and lactate levels. These data suggest that glucose homeostasis is facilitated in late pregnancy by an enhanced availability of gluconeogenic precursors. Whether this metabolic feature is due to a higher protein breakdown or corresponds to a faster recycling of carbon atoms needs further examination. Nevertheless in the case of pigs fed on standard conditions, fat mobilization does not represent an important characteristic in late pregnancy.

Acknowledgments. The authors thank Janine Jung for her excellent technical assistance and Isabelle Coquelet and Martine Fernandez for the careful preparation of the manuscript.

\section{REFERENCES}

1. Battaglia FC, Meschia G 1986 An Introduction to Fetal Physiology. Academic Press, New York

2. Block SM, Sparks JW, Johnson RL, Battaglia FC 1985 Metabolic quotients of the gravid uterus of the chronically catheterized guinea pig. Pediatr Res
$19: 840-845$

3. Murray RD, Jones RO, Johnson R, Meschia G, Battaglia FC 1985 Uterine and whole body oxygen extractions in the pregnant rabbit under chronic steady-state conditions. Am J Obstet Gynecol 152:709-715

4. Johnson RL, Gilbert M, Block SM, Battaglia FC 1986 Uterine metabolism of the pregnant rabbit under chronic steady-state conditions. Am J Obstet Gynecol 154:1146-1151

5. Baur R 1977 Morphometry of the placental exchange area. Adv Anat Embryol Cell Biol 53:1-65

6. Salmon Legagneur E 1965 Quelques aspects des relations nutritionnelles entre la gestation et la lactation chez la truie. Ann Zootech 14:1-137

7. Bergmeyer HU 1974 Methods of Enzymatic Analysis. Academic Press, New York

8. Ho RJ 1970 Radiochemical assay of long-chain fatty acids using ${ }^{63} \mathrm{Ni}$ as tracer. Anal Biochem 36:105-114

9. Campbell RC 1974 Statistics for Biologists. Cambridge University Press, Cambridge

10. Meschia G, Battaglia FC, Hay WW, Sparks JW 1980 Utilization of substrates by the ovine placenta in vivo. Fed Proc 39:245-249

11. Comline RS, Silver M 1976 Some aspects of foetal and uteroplacental metabolism in cows with indwelling umbilical and uterine vascular catheters. J Physiol 260:571-586

12. Ferrell CL, Ford SP, Prior RL, Christenson RK 1983 Blood flow, steroid secretion and nutrient uptake of the gravid bovine uterus and fetus. $\mathbf{J}$ Anim Sci 56:656-667

13. Silver M. Comline RS 1975 Transfer of gases and metabolites in the equine placenta: a comparison with other species. J Reprod Fert 23 (suppl):589594

14. Gilbert M, Hauguel S, Bouisset M 1984 Uterine blood flow and substrate uptake in conscious rabbit during late gestation. Am J Physiol 247:E574E580

15. Peeters LL, Martensson L, Van Kreel BK, Saxena PR, Wallenburg HCS 1986 Movement of oxygen, glucose and lactate across the uterus of the awake near-term guinea pig. Pediatr Res 20:730-734

16. Morriss FH Jr, Rosenfeld CR, Resnik R, Meschia G, Makowski EL, Battaglia FC 1974 Growth of uterine oxygen and glucose uptakes during pregnancy in sheep. Gynecol Invest 5:230-241

17. Hay WW Jr, Sparks JW, Wilkening RB, Battaglia FC, Meschia G 1983 Partition of maternal glucose production between conceptus and maternal tissues in sheep. Am J Physiol 245:E347-E350

18. Reynolds LP, Ford SP, Ferrell CL 1985 Blood flow and steroid and nutrient uptake of the gravid uterus and fetus of sows. J Anim Sci 61:968-974

19. Pethick DW, Lindsay DB, Parker PJ, Northrop AJ 1983 The metabolism of circulating non-esterified fatty acids by the whole animal, hind-limb muscle and uterus of pregnant ewes. Br J Nutr 49:129-143

20. Holzman IR, Lemons JA, Meschia G, Battaglia FC 1979 Uterine uptake of amino acids and placental glutamine-glutamate balance in the pregnant ewe. J Dev Physiol 1:137-149

21. Hard DL, Anderson LL 1982 Interaction of maternal blood volume and uterine blood flow with porcine fetal development. Biol Reprod 27:79-90

22. Ford SP, Reynolds LP, Ferrell CL 1984 Blood flow, steroid secretion and nutrient uptake of the gravid uterus during the periparturient period in sows. J Anim Sci 59:1085-1091

23. Peeters LLH, Grutters G, Martin CB 1980 The distribution of cardiac output in the unstressed pregnant guinea pig. Am J Obst Gynecol 138:1177-1184

24. Meier PR, Peterson RG, Bonds DR, Meschia G, Battaglia FC 1981 Rates of protein synthesis and turnover in fetal life. Am J. Physiol 240:E320-E324

25. Simoes-Nunes C, Duée PH, Pégorier JP, Rérat A 1987 Effect of feed intake level in late gestation on arterial blood concentrations of energy substrates, insulin and glucagon in the chronically catheterized gilt. Reprod Nutr Dev 27:77-87 